\title{
Analysis of the state of vegetation in the municipality of Jagodina (Serbia) through remote sensing and suggestions for protection
}

\author{
Miško M. Milanović ${ }^{A^{*}}$, Veljko S. Perović ${ }^{B}$, Milisav D. Tomićc, Tin LukićD, Snežana S. NenadovićE, \\ Milan M. RadovanovićF, Miloš M. Ninković ${ }^{C}$, Ivan Samardžić ${ }^{A}$, Đurđa Miljković ${ }^{\circ}$ \\ Received: January 12, 2016 | Revised: May 21, 2016 | Accepted: June 2, 2016
}

DOI: 10.18421/GP20.02-03

\begin{abstract}
Both environmental control and appropriate measurement results present basis for the quality protection of geospatial elements. Providing environmental monitoring activities and creating control network is the obligation of each state, whereas local communities provide observation and control of air quality, water quality, waste quality, soil quality, vegetation and land cover control, etc. This has been the reason for the analysis of vegetation of the municipality of Jagodina in Serbia. By processing satellite images, data on the sources of pollution and polluting materials of the vegetation have been discovered. These include spot (stationary), linear (mobile and stationary) and surface (stationary and mobile) sources. While processing satellite images by the Idrisi software, we have acquired results that indicate certain vegetation modifications (images obtained through infrared spectral imaging). Results obtained through remote sensing indicate the necessity to define adequate vegetation monitoring, to complete a register of pollutants, to set up information system and define ways of data presentation in order to manage a single, complete register of environmental pollutants in the municipality of Jagodina.
\end{abstract}

Keywords: environmental control, vegetation, remote sensing, municipality of Jagodina, protection

\section{Introducton}

The Balkan Peninsula is the great hot spot of European biodiversity providing outstanding levels of endemism and refugial habitats (Griffiths, et al., 2004). Outstanding vegetation biodiversity at Balkans is a consequence of specific geographical position, complex geomorphology and Pleistocene climatic fluctuations (Willis, 1994; Tzedakis, et al., 2002; Basarin, et al., 2011; Marković, et al., 2014; Obreht, et al., 2014). However, natural vegetation was dramatically influenced by human activities since Palaeolithic period.
The vegetation conservation and adequate monitoring are great current ecological challenges. In the field of environmental protection and vegetation conservation, contemporary trends must be followed and recent technologies must be applied in order to realize scientific and research aims and tasks. Remote sensing holds an important position in the science of geography. The advantages of remote sensing compared to other scientific methods are evident in the fact that occurrences and processes on the Earth's surface are observed without direct contact, vast areas are inves-

\footnotetext{
A Department of Geospatial Bases of Environment, Faculty of Geography, University of Belgrade, Belgrade, Serbia

B Institute of Soil, Teodora Drajzera 7, Belgrade, 11000, Serbia

C Service for the protection and advance of environment, Mining basin Kolubara, Lazarevac, Serbia

D Department of Geography, Tourism and Hotel Management, Faculty of Sciences, University of Novi Sad, Novi Sad, Serbia

E Laboratory for Material Science, Institute of Nuclear Sciences "Vinča", p. fax 522, University of Belgrade, Belgrade, Serbia

F Geographical Institute "Jovan Cvijić", Serbian Academy of Sciences and Arts - SASA, Belgrade, 11000, Serbia

G Faculty of Aplied Ecology, Futura, University of Singidunum, Serbia

* Corresponding author: Miško M. Milanović, e-mail: misko@gef.bg.ac.rs
} 
tigated; field observation is decreased, but not completely excluded, etc. Results of remote sensing can be acquired through specially designed software applications for image processing, whose main role is to interpret remote-sensed images photographically. For this reason and for the purposes of this paper, the Idrisi software has been used. Its main advantages are the following: integration of all information from a certain area, design of environmental maps, which is considered an important factor for monitoring environmental conditions of a certain area, design of $3 \mathrm{D}$ images of a certain terrain, catastrophes simulations and prediction of their consequences, the possibility of creating a comprehensive set of relevant socio-political information and their integration into an easily accessible system for public use, and environmental control and management (Milanovic, Ljesevic, 2009; Jovanović, et al., 2015; Bjelajac, et al., 2016; Lukić, et al., 2016).

In this study we apply remote sensing techniques to analyse vegetation status in the municipality of Jagodina, central Serbia.

\section{Geographical setting}

The municipality of Jagodina extends over $470 \mathrm{~km}^{2}$; it encompasses 54 settlements and borders seven other municipalities. It is situated in the River Belica Basin in Central Pomoravlje Region of Central Serbia. Its geographical position is $43^{\circ} 59^{\prime}$ north and $24^{\circ} 14^{\prime}$ east, with the lowest point at $110 \mathrm{~m}$, and the highest at 707 $\mathrm{m}$. Favourable physical and geographical conditions of the district have influenced the development and expansion of the settlements, which, in turn, has had negative effects on the condition of the environment. Industry, which was at its height during the eighties of the previous century, induced the degradation of physical and geographical elements of the environment, notably the vegetation. At the time, the industry had influence on the modification of the vegetation condition of the district of Jagodina, but the pedological land cover influenced the development of specific plant species. Unfortunately, some of them are at risk of extinction. Pedological land cover and favourable hydrological conditions have influenced diversity of the vegetation. Smonitza (Vertisol) spreads over the largest part of the territory of Jagodina district, at the altitude zone of 200-300 meters above the sea level, thus occupying, in this particular case, the southwest and central part of the municipality. This type of height positioning is quite expected since it is encountered at river and lake plateaus, which went through underwater, hydromorphic - meadow, and meadow phase during their development. We could suppose that much larger areas of the district were covered in smonitza in the past. However, they were transformed into other types of soil due to pedogenetic factors. Satellite images of this type of soil have disclosed some agricultural species.

According to its altitudinal zone distribution, Eutric brown soil (Eutric Cambisol) is located between 150-400 meters above the sea level. This type of soil is formed in semi-humid areas whose average annual rainfall is $600-700 \mathrm{~mm}$, its summers are dry and average annual temperatures are between $10^{\circ}-12^{\circ} \mathrm{C}$, while its fundamental substrata consist of lake and river sediments composed of loam. We could suppose that this type of soil was formed through the metamorphosis of smonitza, thus being much drained, permeable type of soil, with porosity of $55 \%$. It is widespread in the areas where oak forests existed previously. This type of soil is located in the areas of rolling hills, thus enhancing the possibility of its usage in farming, vegetable and fruit growing, and viticulture. However, pine, large-leaved lime, acacia, great maple, common oak, birch, hybrid plane and white poplar are present in this area.

Alluvial and diluvial deposits, which are very noticeable in the district, are the result of combined effects of fluvial processes and diluvial erosion of slopes. Alluvial deposits are mostly formed on alluvial inundation plains and river plateaus as the results of accumulation of river materials during the high water level. These are predominantly areas at confluences of raging torrents.

Analysis of the vegetation cover is in compliance with the goals of the CORINE programme and is performed according to the guidelines for the five units of the vegetation study: construction land, agricultural land, forests and semi-natural areas, areas covered with water and water areas (Di Gregorio, Jansen, 1998). Three goals of the CORINE programme are: 1. Informing of the member states on the environmental condition and the main problems they are faced with; 2. Exchange of information between the member states; 3. Providing of the confidential and compatible information. Those three goals were set up in 1985 (June 27) when the European Union Council has adopted the blueprint for the CORINE programme (implementation started in 2004).

Results of remote sensing have demonstrated to the authors the indicators of the present state of the environment and the effects upon it. Therefore, certain control and protection measures for the vegetation cover of the municipality of Jagodina have been proposed as well as views of the effects on the environment (compared to the previous state). Furthermore, a vegetation register of the district of Jagodina has been completed in order to define qualitatively the ways of presenting data necessary for the completion of a sin- 


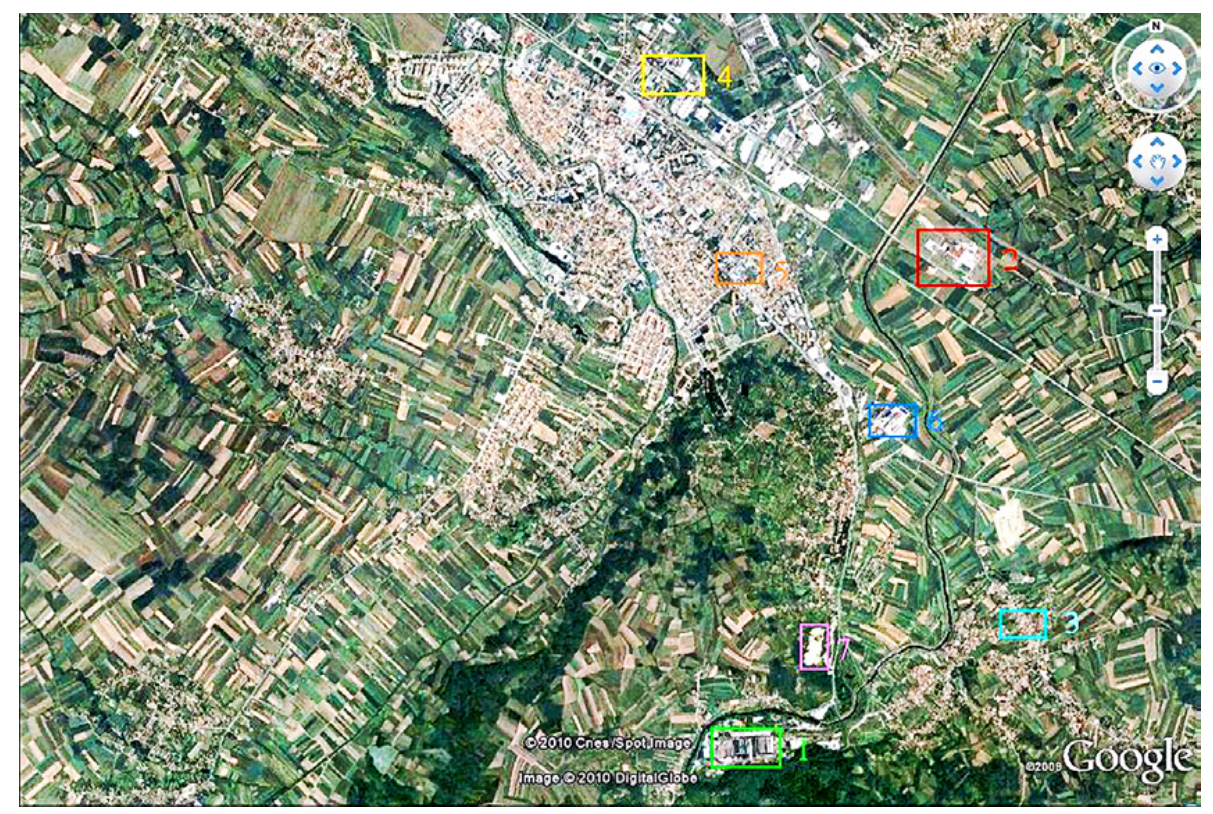

Figure 1. The most endangered areas on the territory of the town of Jagodina. Explanation: 1. Cable factory 2. Juhor 3. Metalka majur 4. Žitomlin 5. Brewery 6. Slaughterhouse 7. Quarry

Source: Google Earth, 2010, revised and expanded version

gle, complete environmental register of this Serbian municipality together with the organization of the information system for the environmental management.

\section{Materials and methods}

Quantitative methods, analysis and synthesis, classification and other methods applied in the research, had to be adjusted with the aim of the research so that the results of remote sensing were valid.

The Idrisi software which has been used for the analysis of satellite images, presents a collection of over 150 modules that are connected by a single system through which they enable the input, display and analysis of geospatial data (Eastman, 2001). The broadest modules, within which the other modules are placed, present the core modules where the fundamental means of input, maintenance, management and display of raster images are provided; analytical ring modules where the main sets of means for the analysis of the raster graphical data are provided (processing of the remote-sensed images), and outer modules that enable transformation of data from the Idrisi programme into the other programmes, where the data format conversion is performed. This module is convenient for the input of satellite images acquired from a certain number of satellites. In this case, for the purposes of this paper, satellite images obtained from the 14 channels of the Aster satellite have been used. The municipality of Jagodina is located in the southeast part.

The values of the data acquired in the southeast part of the image - a part where the municipality of
Jagodina is situated, have been compared with the deciphered data from the Google Earth image in order to establish, as far as it is possible, the present state of the vegetation. The reason for this lies in the fact that the images obtained from the Aster satellite were purchased in 2007. By classifying the image content and the use of micro modellers, both quantitative and qualitative data on the vegetation of the district have been obtained.

The analysis of the satellite images in the Idrisi software implied image restoration and input, image resolution zoom and enhancement, image classification and image transformation. Image restoration implied radiometric and geometric corrections, elimination of errors, which were the result of certain atmospheric conditions, georeferencing, and the like. Enhancement techniques implied image contrast adjustment, noise removal and resolution regulation. Classification tools have been used for the class definition of each pixel, while transformation techniques provided different levels of colour transformation in space (relation: colours intensity, colour saturation), levels for the structural analysis and finally, created the vegetation contents of the municipality of Jagodina. (Milanovic, et al., 2008).

For the analysis of the vegetation cover infrared images that were created in the near and medium infrared spectral zone have been used. At the images acquired in the near infrared spectral channel, the vegetation is displayed in light red shades, whereas at the images acquired in the medium infrared channel, the vegetation is displayed in dark red shades. Vegetation 


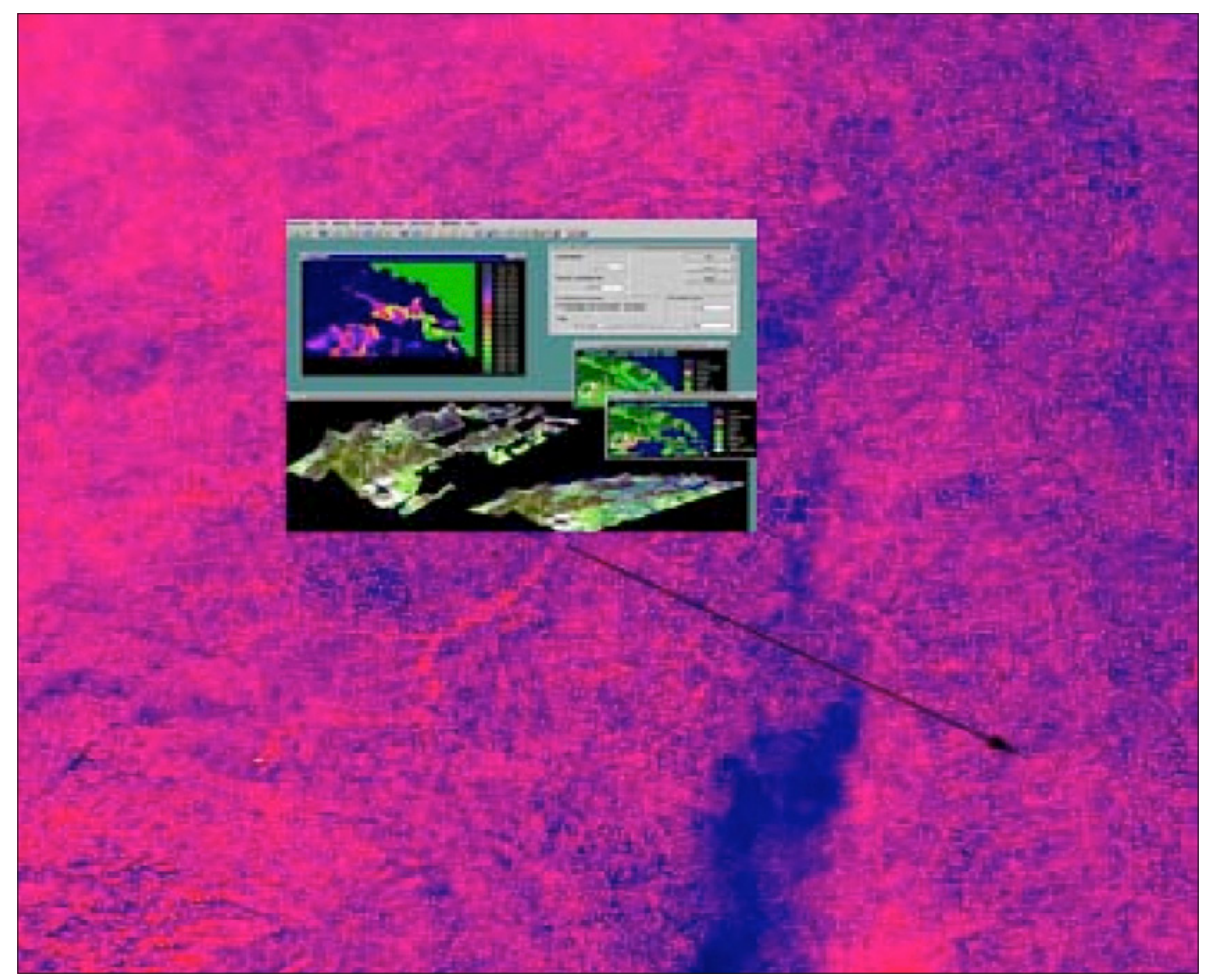

Figure 2. Differentiation of the vegetation contents of Jagodina through the use of the macro modeller. Differentiation in the Idrisi software

can be detected at the images by its specific appearance and shades, which are distinctive for every plant species.

At the image presented, a pseudo colour composite $3 \mathrm{n} 45$ is obtained through the merging of the images taken in the near infrared spectral channel $-3 n$, and the two images acquired in the medium infrared spectral channel -4 and 5 . The combination that resulted in the merging of images and the image composite was appropriate for recording of the plant species and their amounts.

The pseudo $3 \mathrm{~b} 45$ (caption 4) is obtained through the merging of the images taken in the near infrared spectral channel $-3 \mathrm{n}$, and the two images acquired in the medium infrared spectral channel -4 and 5 . It was especially convenient for detecting diseased vegetation i.e. the one where there is not enough water in treetops.

Channels $3 \mathrm{n}$ and $3 \mathrm{~b}$ (VNIR sensor - Visible Near Infra Red) are convenient for analysing types of trees, space between branches in treetops, analysing the structure and composition of the treetops, analysing the age, analysing forest soil, analysing clearings, and the like. The obtained data are the input for the analysis of degraded vegetation. Displayed colour combinations (acquired through the image processing by the Idrisi software), enabled deduction of the arrangement of higher undergrowth in the mountainous area of the southeast part of the district. Low undergrowth and bushy vegetation have been detected in the riv- erbank area of the Velika Morava. In the image composite where the VNIR 3 b image was used, thick forests (monolithic forests) were presented in the light red shade, while low undergrowth was displayed in dark red shade. In the composite where the image obtained in VNIR channel 3 n, red shades are used for the presentation of vegetation, whereas blue-purple shades were used for displaying agricultural species dispersed over the loose pedological cover. The possibilities for image analysis were much broader when the spatial resolution of the image was wider and of higher quality.

Detected vegetation at the images, deciduous forests, coniferous forests, undergrowth, orchards, vineyards, agricultural species, single trees and the like, were differentiated according to their shape, texture and colour shades (hues of red colour). Deciduous forests that were detected at the images were displayed in the exceptionally kidney-like structure (Kušan, 1996), with the shadows displayed in irregularly curved shapes. They were distributed over the entire area of the district. Birches and poplars were displayed in lighter red shades; ash is darker, and oak in the darkest. Conifers were displayed in very dark shades of red, in curved shapes, with cone shaped shadows. They were detected in the west part of the district and less in the southeast part. Treetops influenced to some extent the contrast degree of the image, with the treetops being thicker in the west and southwest part (when observing in nature $25 \%$ of sunbeams 


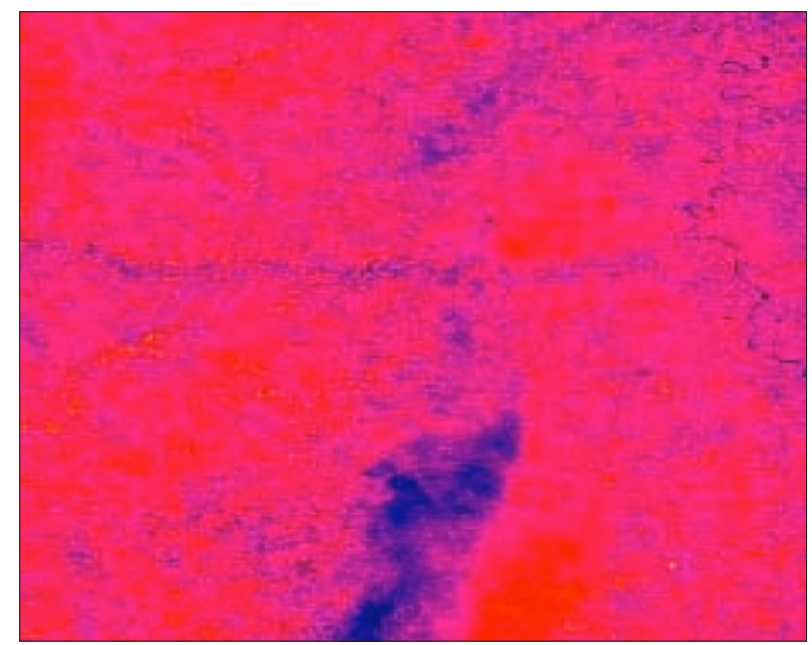

Figure 3. Determination of the treetop density and detection of water shortage in treetops. Differentiation in the Idrisi software

go through tree branches) where the image contrast is higher, the shadow shape is more evident, the treetop shape is more differentiated and the image itself is more accurate (Folving, et al., 1993). Besides thick treetops, there are medium dense treetops, where 50\% of sun light goes through branches and thin treetops and the other $50 \%$ of sun light goes through treetops and reaches the pedological cover.

In the central parts of the district and on the northeastern border of the municipality of Jagodina, the image contrast is less precise, so certain segments are blurred and incomprehensible. Nevertheless, they were still analysed (in these parts the resolution of the image is decreased). In order to calculate the complete forest cover, it was necessary to determine the degree of the treetop density (Tomppo, 1992) for every type of plant.

Solitary trees, mostly poplars and planes that are situated by roads and streets in urban areas were detected as dark red spots at regular distance. Orchards are organized in regular distinctive geometric lines, usually in proximity to rural settlements in the south and southwestern part of the district. Vineyards were detected in the southwestern and northwestern part of the municipality.

Mixing of colours from the wider range of analysis, implies energy reflecting from single elements at the surface of the Earth, practically, foreign matter that covers vegetation - polluting substances. All the elements merged at the image composite are in direct proportion with the surface of each pixel itself (Chabrillat, et al., 2002). As an example, we have taken colours that depict vegetation and land without vegetation (linear character), and later, we have merged single channels and produced a mixed spectrum within the spectral space itself. Spectral channels gain certain values i.e. quantification of every smallest image unit is obtained, thus producing hypothetically in the computer programme, the spectral space that has unitary dimensions for every image acquired from a particular channel as well as the units of measure between different spots in space. Within the spectral space, every peripheral spectrum defines the end of a colour mixture at the image composite (two or more spectra).

Layers of raster data are described through a precise raster grid of cells, where each cell has a numerical value that presents the very essence of vegetation type location (Eastman, 2001). Vector data are created on the basis of the raster data used by the authors of the paper and are presented in the form of maps.

\section{Results and discussion}

Detection of the modified state of vegetation, the overall environmental research as well as and cure of the endangered environment belong to a multidisciplinary field of research. Successful environmental protection through remote sensing is evident in the systematic observation - systematic monitoring. The more developed control system, the more successful protection is.

Activities that detect sources of pollution and polluting materials of the vegetation cover, have detected spot (stationary), linear (mobile and stationary) and surface (stationary and mobile) sources. Public transport (exhaust fumes from the internal combustion engines), individual fossil fuel furnaces, building activities, town waste disposal landfill (which is situated 1.5 kilometres from the town centre), low frequency electromagnetic radiation emitted from various sources of mobile networks base stations on the town's territory, telecommunication receivers, low-voltage and high-voltage substation networks, town's heating plant (gas), and the industry have most influence on the vegetation. Due to the closure of some industrial plants or the decreased production in others, the emission of dangerous and damaging matters from the production plants has been lowered.

The forest cover of the Velika Morava riverbank area is either isolated or the trees are positioned close to each other with their branches touching. In the forest cover of the south and southeastern parts, side treetops touch at a higher or lower degree, and one-level forest is observed in that area (northwestern part of the district). The cover is differentiated according to its width (in a monolithic forest, the width of the cover is the narrowest). The differences in the height of the trees and the height of the treetops between all trees are smaller, and therefore, horizontal fusion is observed. Where trees grow less densely (east part of the image), pedological cover is well detected in the image. In two-level forests where the peaks of the treetops at the first level touch 


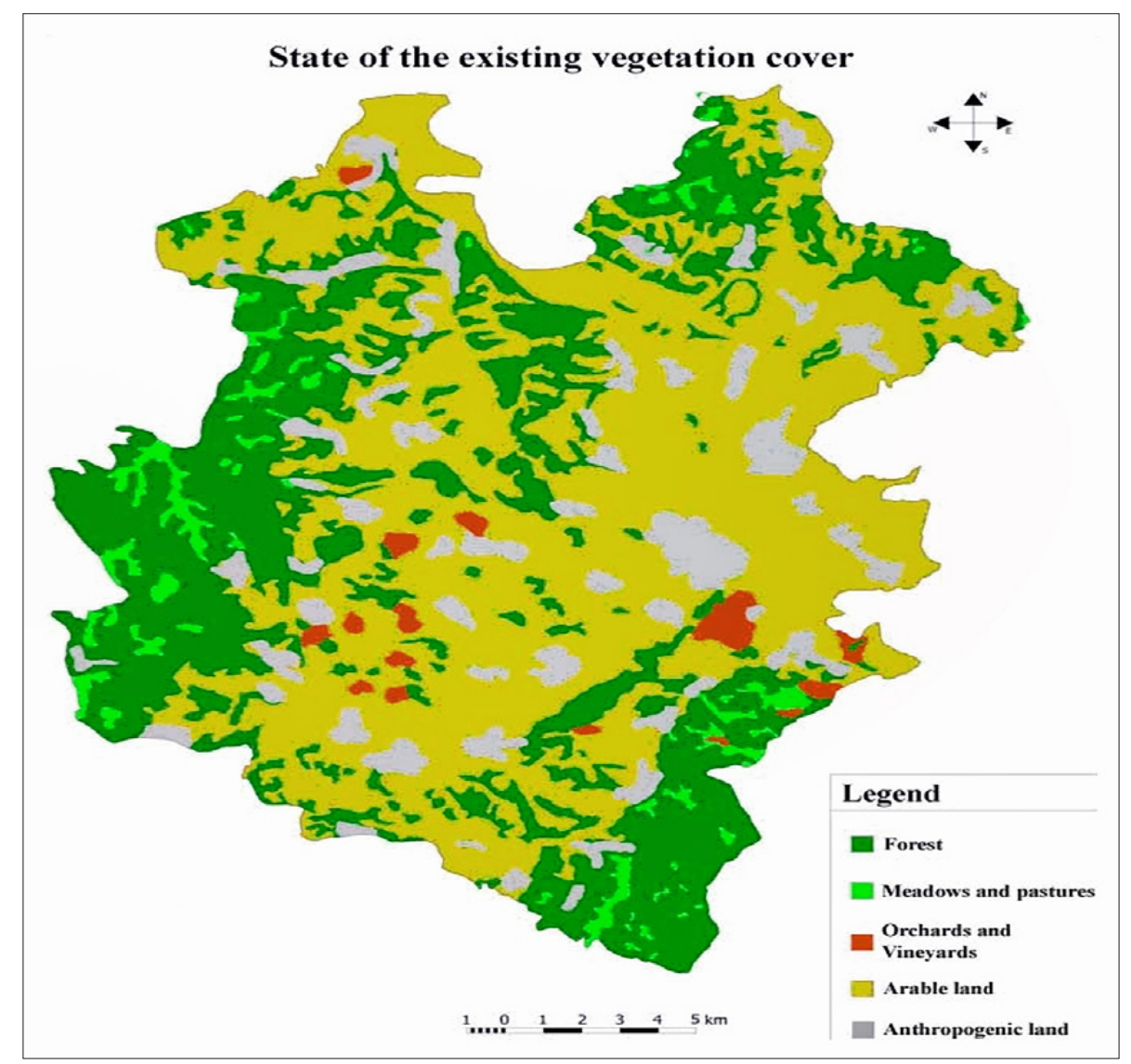

Figure 4. State of the existing vegetation cover in the municipality of Jagodina. The map was designed on the basis of the analysis of the images purchased in 2007

the lower parts of the treetops of the second level, vertical fusion is clearly distinguished (the trees seem to be the whole) (Milanović M., Lješević M., 2004). Two-lev- el forests are not present at a higher degree in the municipality of Jagodina, thus making polluting matters on trees easily identified.

Table 1. Vegetation register

\begin{tabular}{|c|c|c|c|c|c|c|c|}
\hline No. & Species & Number of trees & Dry & No. & Species & Number of trees & Dry \\
\hline 1 & Pinus nigra & 361 & 1 & 19 & Quercus cerris & 3 & \\
\hline 2 & Tillia grnadifolia & 91 & 1 & 20 & Morus mill & 3 & 1 \\
\hline 3 & Robinia pseudoacacia & 88 & 1 & 21 & Taxodium districhum & 3 & \\
\hline 4 & Acer campestre & 70 & & 22 & Fraxinus excelsior & 5 & \\
\hline 5 & Ulmus effuse & 54 & 1 & 23 & Tillia argentea & 2 & \\
\hline 6 & Gledisia triacanthos & 21 & & 24 & Salix alba & 2 & \\
\hline 7 & Fraxinus angustifolia & 19 & & 25 & Morus alba & 2 & \\
\hline 8 & Prunus mill & 15 & & 26 & Corylus avellana & 2 & \\
\hline 9 & Betula verrucosa & 14 & & 27 & Prunus cerasifera & 2 & \\
\hline 10 & Quercus robur & 14 & & 28 & Pseudotsuga menziesi & 2 & \\
\hline 11 & Piea abies & 13 & & 29 & Crataegus monogyna & 2 & \\
\hline 12 & Juglans regia & 13 & & 30 & Acerpseudoplatanus & 2 & \\
\hline 13 & Acer negundo & 13 & & 31 & Acer tataricum & 9 & \\
\hline 14 & Pinus silvestris & 14 & & 32 & Cornus mas & 1 & \\
\hline 15 & Catalpa bignonioides & 9 & 2 & 33 & Pyrussp & 1 & \\
\hline 16 & Populus alba & 6 & 1 & 34 & Cerasus avium & 1 & \\
\hline 17 & Platanus acerifolia & 5 & & 35 & Cerasus avium & 1 & \\
\hline 18 & Taxus baccata & 4 & & 36 & Aesculus hippocastan & 1 & \\
\hline
\end{tabular}


Coniferous forests in the west and southwestern part are 40-60 years old, and their treetops are sharper, while angularity of pines in the young pine forests is not so prominent.

Common oak (Quercus robur) in the village of Kolare near Jagodina presents a rare example of planted common oak. It was planted 150 years ago and today it is characterised by the following exceptional traits: its total height is $21.5 \mathrm{~m}$, its trunk diameter is $1.32 \mathrm{~m}$ and the diameter of its broad balanced treetop is $25 \mathrm{~m}$. According to that, it presents a textbook example of a successful growth of a species in its typical natural habitat. The rolling countryside under the Juhor mountain, around the river Lugomir and near the village of Kolare, was once the area covered with common oak and field ash forests. Common oak has great importance for the inhabitants of Serbia as a symbol of folk gatherings and is very often referred to as a 'holy tree - the testament'.

Common oak is found in the valley of the Velika Morava River, on its left bank, close to the riverbed. Common oak is a typical species for the low-lying oak and ash forests that once spread widely in the floodplains of the Sava, Drina and Morava rivers and their tributaries. These areas belong to the zone of floodplain marsh and hydrophilic forests. The reasons for destruction of these forests are the supply of building wood material and the expansion of arable land.

Concerning the division of the altitudinal vegetation zones, this type of forest belongs to the oak region, although extremely immense anthropogenic influence has provoked significant modifications in the composition of flora. At the images showing the neigh-

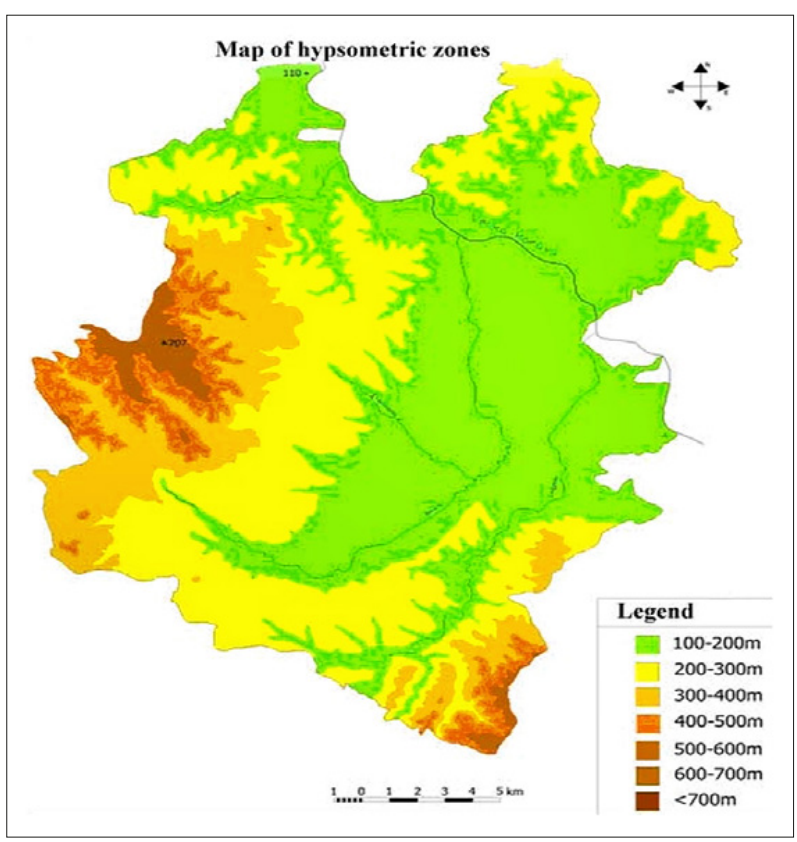

Figure 5. The importance of the hypsometric strips for the vegetation distribution. The map was designed on the basis of the analysis of the images purchased in 2007 bouring areas of the town of Jagodina, pine, lime, acacia, common oak and other species of various size and age were detected. Over 40 various species of trees have been detected in the district with large-leaved deciduous trees being more common than high conifer trees. Besides pine trees (Pinus nigra) there are also large-leaved lime trees (Tillia grandifolia). Unlike the pine trees which are arranged in groups, lime trees are positioned regularly. Other species that are also very numerous on the territory of the municipality of Jagodina, are: acacia, great maple, common oak, birch, hybrid plane, white poplar, and others.

Suggestions for the protection measures must be completed with the register of pollutants for the spot, linear and surface pollutants and polluting matters and energies, indicating the ordinal number of pollutants, parameters being listed, quantities, units of measurement, etc.

Table 2. A part of the measurement register of pollutants that have the indirect influence on the vegetation condition

\begin{tabular}{|c|l|c|}
\hline No. & Parameters & Unit of measurement \\
\hline 1. & Maximum flow & $\mathrm{l} / \mathrm{s}$ \\
\hline 2. & Medium flow & $\mathrm{l} / \mathrm{s}$ \\
\hline 3. & Minimum flow & $\mathrm{l} / \mathrm{s}$ \\
\hline 4. & Air temperature & ${ }^{\circ} \mathrm{C}$ \\
\hline 5. & Water temperature & ${ }^{\circ} \mathrm{C}$ \\
\hline 6. & Colour & $\mathrm{mg} \mathrm{Pt/l}$ or descriptive \\
\hline 7. & Smell & descriptive \\
\hline 8. & Visible matter & Descriptive \\
\hline 9. & PH & $\mathrm{ml} / \mathrm{l}$ \\
\hline 10. & Deposits (after 2 hours) & $\mathrm{mg} / \mathrm{l}$ \\
\hline 11. & Dry residue & $\mathrm{mg} / \mathrm{l}$ \\
\hline 12. & Stoked residue & $\mathrm{mg} / \mathrm{l}$ \\
\hline 13. & Stoking loss & $\mathrm{mg} / \mathrm{l}$ \\
\hline 14. & Suspended matter & $\mu \mathrm{S} / \mathrm{cm}$ \\
\hline 15. & Electrical conductivity &
\end{tabular}

We have defined suggestions for control measures of the vegetation cover in the municipality of Jagodina basing our conclusions on the shades and colours of the vegetation cover, contents of the image (photo texture), phenological aspect and final processing of the satellite images.

Control measures would imply the following:

- Defining biomass by a surface unit of the image;

- Quantifying the ratio between biomass, land topography and hydrological conditions;

- Defining water composition in the treetops (diseased vegetation);

- Defining water composition in soil;

- Deciphering composition conditions; 


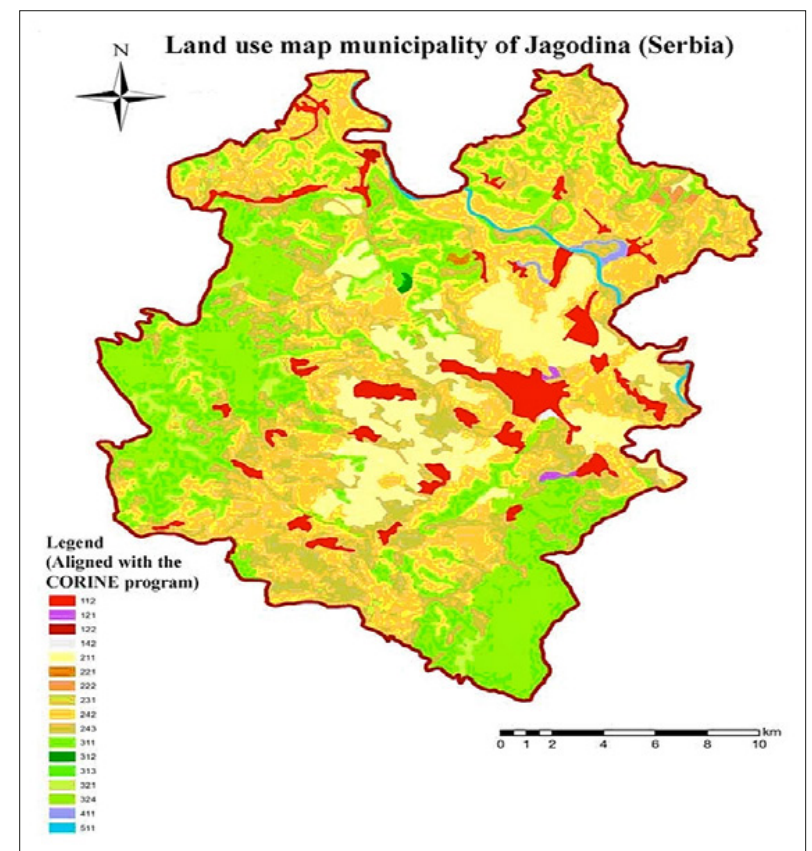

Figure 6. Possibility of the estimate of the vegetation degradation based on the analysed images. The map was designed on the basis of the analysis of the images purchased in 2007

- Studying gaps in treetops;

- Cataloguing of the forest cover that implies specifying modifications, use and organization of the forest;

- Preventing conditions that might induce forest fires (especially coniferous forests).

Quality control would imply systematic measurement, studying, evaluation indicators of the state and detection of the vegetation degradation. Then, it would imply forming of the vegetation monitoring network, measurement of the emission and imission in order to observe quality and degree of pollution, analysis of the effects on people's health, studying soil quality, organizing control of communal waste, dangerous waste and waste that has secondary raw material characteristics, organizing control of the quantity and quality of waste waters, continual environmental, urban and building control, etc.

\section{Conclusion}

Having analysed remote-sensed images and terrain data, we have observed certain problems connected with the vegetation degradation, which have anthropogenic origin.

The CORINE programme must be applied at the territory of the municipality of Jagodina in order to monitor the state and control quality of the environment, and acquire the data on the environment condition, geographic distribution and variety of flora and fau- na, quality and quantity of water resources, structure of the pedological cover and soil condition, amount of polluting particles in the environment (liquid, solid and gas substances), natural disasters, hazards and the like. Data acquired through the CORINE programme are standardized, complete and continuously updated. By using these data, it is very easy to comprehend the existing state of the vegetation cover, recognize sources and potential sources of pollution. Based on the information obtained, it is possible to implement measures for the cure of the present state and establish the system of preventive measures of protection.

It is possible to establish a monitoring system that would enable observation of the condition of all environmental elements and would enable prompt reaction on the territory of the municipality of Jagodina. It is of utmost importance to observe soil and vegetation state because agriculture is the most developed type of industry in this region and the use of pesticides is widespread but inappropriate due to the unqualified use by the local population and the lack of control by the state.

The CORINE programme would enable continual monitoring, comparison of the state of the environment with the other municipalities and more active engagement by the local authorities to sanction all forms of environmental degradation and changes to land use initiated by depopulation in rural areas of the municipality of Jagodina.

\section{Acknowledgement}

This research was supported by the Project 114- 4512080/2016 of Provincial Secretariat for science and technological development, ECAP Vojvodina.

\section{References}

Basarin, B., Vandenberghe, D.A.G., Marković, S.B., Catto, N., Hambach U., Vasiliniuc, S., Derese, C., Rončević, S., Vasiljević Dj.A., Rajić, Lj. 2011. The Belotinac section (Southern Serbia) at the southern limit of the European loess belt: preliminary results. Quaternary International 240, 128-138.

Bjelajac, D., Mesaroš M., Schaetzl R.J., Pavić D., Micić T., Marković R.S., Gavrilov, M.B., Perić, Z., Marković S.B. 2016. Geographica Pannonica 20, 1-7. Chabrillat, S., Goetz, H., Krosley, L. and Olsen, W. 2002. Use of hyperspectral images in the identification and mapping of expansive clay soils and the role of spatial resolution. Remote Sensing of Environment 82, 431-445.

Di Gregorio, A., Jansen, L. 1998. Land Cover Classification System (LCCS) - Classification Concepts and User manual for software version 1.0, FAO-Rome. 
Eastman, R.J. 2001. IDRISI32 Release 2 - Tutorial, Clark Labs, Clark University, Worcester, MA, USA.

Folving, S., Megier, I., Wilkinson, G.G. 1993. Application of Remotely Sensed Data in Forestry, Grassland and Natural Vegetation Management in European Less Favoured Areas, Case Studies to Ecosystem Mapping, International Symposium Operationalisation of remote sensing, Vol. 8, ITC, Enschede, Holland.

Griffiths, H. I., Kryštufek, B., Reed, J.M. (Eds.) 2002. Balkan Biodiversity - Pattern and Process in the European Hotspot, Springer, pp 343.

Jovanović, D., Govedarica, M., Sabo, F., Bugarinović, Ž., Novović, O., Beker, T., Lauter, M. 2015. Land Cover change detection by using Remote Sensing A Case Study of Zlatibor (Serbia). Geographica Pannonica 19, 162-173.

Kušan, V. 1996. Mapping forests using Landsat TM satellite imagery, University of Zagreb, Faculty of Forestry, Zagreb.

Lukić, T., Leščešen, I., Sakulski, D., Basarin, B., Jordaan, A. 2016. Rainfall erosivitiy as an indicator of sliding occurrence along the southern slopes of the Bačka loess plateau: A case study of the Kula settlement, Vojvodina (North Serbia). Carpathian Journal of Earth and Environment Sciences 11, 303-318.

Marković, S.B., Korać, M., Mrđić, N., Buylaert, J.P., Thiel, C., McLaren, S.J., Stevens, T., Tomić, N., Petić, N., Jovanović, M.,Vasiljević, Dj.A., Sümegi, P., Gavrilov, M.B., Obreht, I. 2014. Palaeoenvironment and geoconservation of mammoths from the Nosak loess-palaeosol sequence (Drmno, northeastern Serbia): Initial results and perspectives. Quaternary International 334-335, 30-39.
Milanović, M., Lješević, M. 2004. Application of Remote Sensing in the Environmental Managing, First Mediterranean Conference on Earth Observation-Remote Sensing (MeCEO), Faculty of Mining and Geology, Remote Sensing Centre, Belgrade University, Belgrade, 253-258.

Milanovic, M., Ljesevic, M., Bakrac, S., Novkovic, I. 2008. Possibility Analysis of Vegetation Processing Satellite Images of Infrared Spectrum, Proceedings of the gth International Conference on Fundamental and Applied Aspects of Physical Chemistry, Volume II, Physical Chemistry 2008, Belgrade, 662-664.

Milanovic, M., Ljesevic, M. 2009. Methods of Remote Sensing in Environment, University of Belgrade, Faculty of Geography, Belgrade, 1-274.

Obreht, I., Buggle, B., Catto, N., Marković, S.B., Bösel, S., Vandenberghe, D.A.G., Hambach, U., Svirčev, Z., Lehmkuhl, F., Basarin, B., Gavrilov, M.B, Jović, G. 2014. The Late Pleistocene Belotinac section (southern Serbia) at the southern limit of the European loess belt: Environmental and climate reconstruction using grain size and stable $\mathrm{C}$ and $\mathrm{N}$ isotopes. Quaternary International 334-335, 10-19.

Tomppo, E. 1992. Satellite image aided forest site fertility estimation for forest income taxation - Acta forestalia fenica, The Society of forestry in Finland.

Tzedakis, P.C., Lawson, I.T., Frogley, M.R., Hewitt, G.M., Preece, R.C. 2002. Buffered Tree Population Changes in a Quaternary Refugium: Evolutionary Implications. Science 297, 2044-2047.

Willis, K.J. 1994. The vegetation history of the Balkans. Quaternary Science Reviews 13, 769-788. 